\section{Cureus}

\title{
Human Nocardia Infections: A Review of Pulmonary Nocardiosis
}

\author{
Venkataramana Kandi ${ }^{1}$ \\ 1. Department of Microbiology, Prathima Institute of Medical Sciences
}

$\square$ Corresponding author: Venkataramana Kandi, ramana20021@gmail.com

Disclosures can be found in Additional Information at the end of the article

\section{Abstract}

Human nocardiosis may present as an acute or a chronic infection. Although a saprophyte Nocardia spp are responsible for superficial skin infections, pulmonary infections, and disseminated nocardiosis usually involving patients who are immunosuppressed and debilitated. Infections in immunocompetent individuals are usually chronic and present nonspecific symptoms. Invasive and disseminated nocardiosis is common among patients with weakened cellular immune systems. Clinical diagnosis of pulmonary nocardiosis is difficult owing to the similarity of its presentation with other respiratory pathogens that include Actinomycetes members and Mycobacterium tuberculosis. Laboratory diagnosis of human nocardiosis is plagued by the fact that a culture of Nocardia spp requires prolonged incubation periods for isolation which most laboratories fail to follow. The lack of clinical, laboratory, and epidemiological data on the incidence of nocardiosis in humans undermines its significance as a potential pathogen. This review attempts to reexamine the pathogenic potential of Nocardia in human infections

Categories: Infectious Disease, Pulmonology

Keywords: human nocardiosis, pulmonary nocardiosis, laboratory diagnosis of nocardia infections

\section{Introduction And Background}

The bacteria most commonly associated with chest infections include Haemophilus influenzae, Klebsiella pneumoniae, and Streptococcus pneumoniae, and these are the targets of antimicrobials prescribed by a physician when treating chest infections. Chest infections are also caused by other bacterial species that include members of Actinomycetes, Bordetella pertussis, Mycoplasma pneumoniae, and Coxiella spp, which are difficult to cultivate in most laboratories [1-2]. The treatment in the case of respiratory tract infections is usually blind owing to the lack of reliable results from the sputum culture. A sputum culture should not be dismissed as valueless. If carried out correctly, it can be helpful in the management of chest diseases like acute bronchitis, chronic bronchitis, bronchiolitis, bronchiectasis, chronic pulmonary obstructive disorders (COPD), pneumonia, and cystic fibrosis, particularly when they are chronic in nature and recurrent. Using a set of a few enriched, selective and differential media, the organisms present are self-identifying and are reliably isolated. A laboratory report consisting of the identity of the bacterium and its antimicrobial sensitivity pattern can then be issued to the physician. The organisms isolated may be predictable, but with the emergence of resistance to commonly prescribed antibiotics, a specific sensitivity result is essential for guiding appropriate antimicrobial treatment [3-4].

The potential pathogens in cases of chronic chest infections are Haemophilus influenzae and Streptococcus pneumoniae followed by Klebsiella pneumoniae, Staphylococcus aureus and 
Pseudomonas spp. Streptococcus pneumoniae is the most common isolate in cases of pneumonia and in cystic fibrosis cases Pseudomonas spp and Staphylococcus aureus are frequent isolates. Haemophilus influenza is commonly isolated in acute bronchitis and bronchiectasis cases usually in children, young adults and geriatric age patients. Tuberculosis is another most important lower respiratory tract infection affecting lungs and usually causes infections in immunocompromised, debilitated and nutritionally deprived individuals [5]. Other causes for chest infections include microorganisms of fungal and viral origins. Aspergillus spp (mostly $A$ flavus and A fumigatus), Candida spp, and Cryptococcus spp cause pulmonary infections usually in immunocompromised patients, which include HIV/AIDS (human immunodeficiency virus infection/acquired immunodeficiency syndrome) patients [6-7]. Most viral respiratory tract infections predispose individuals to secondary bacterial or fungal infections necessitating antimicrobial therapy.

\section{Review}

Nocardia spp belong to the aerobic actinomycetes group (Phylum: Actinobacteria, Order: Actinomycetales) of bacteria which are gram-positive bacilli showing branching filamentous forms, are non-spore forming, and mildly acid-fast bacteria [1]. These bacteria are saprophytic and are found in soil and water [2]. Among more than 85 identified species of Nocardia, approximately 25 species are associated with human infections and include Nocardia asteroides complex (more than $50 \%$ human cases), $N$. brasiliensis, $N$. abscessus, $N$. cyriacigeorgica, $N$. farcinica, $N$. nova, $N$. transvalensis complex, $N$. nova complex, N. pseudobrasiliensis, and the recently reported Nocardia veteran and $N$. cerradoensis [8-9]. Human infection with Nocardia can result due to inhalation (pulmonary nocardiosis-pneumonia, lung abscess, and cavitary lesions) or contact with the bacteria via a cut or abraded skin (cutaneous nocardiosiscellulitis, ulcers), and the infection can then disseminate to the brain, kidneys, joints, heart, eyes, and bones [10-13]. Nocardia spp may also result from hospital-acquired infections, usually involving catheterized patients and those who undergo surgeries (postoperative infections) [14]. Human-to-human transmission is not documented. Pulmonary infection with Nocardia spp show clinical symptoms similar to those suspected with pulmonary tuberculosis (fever, cough, chest pain, night sweats, weight loss and pneumonia) [15]. Infections with Nocardia spp usually occur in individuals with weakened immune system and can include patients suffering from diabetes, malignancies, HIV/AIDS, lung disorders like pulmonary alveolar proteinosis (plugged lung air sacs), individuals with connective tissue disorders, chronic alcoholism, transplant patients, and patients on corticosteroid therapy. In developing countries, including the United States of America, it has been noted that more than $60 \%$ of human nocardiosis occurs in immunocompromised individuals and that males are more prone to infection than females $(3: 1)$ $[8,16-21]$. The data on human nocardiosis is limited in the literature and is usually present as isolated case reports undermining its significance in human infection [22-24]. Persistent and disseminated human infection with Nocardia cyriacigeorgica in an otherwise immunocompetent individual was reported recently in the literature which was treated employing a strategic combination therapy that lasted for more than a year. It has been noted that a delay in diagnosis among immunosuppressed patients infected with Nocardia may be responsible for treatment failure and poor prognosis [25]. Another report which reviewed the history of human nocardiosis has revealed that clinicians should suspect infection with Nocardia and notify the same to the laboratory so that the necessary steps are taken by laboratory specialists to isolate, identify, and sensitivity pattern of the Nocardia spp [26]. Co-infection with Nocardia spp in patients suffering from mycobacterial lung infection highlight the importance of laboratory diagnosis that may facilitate better patient management [27]. A previous study has also elaborated on the types of radiological findings in pulmonary nocardiosis that include consolidation of the lungs, presence of nodules and masses, pleural effusion, and extension of lung infection towards the chest wall resulting in abscess [28]. A very recent research report has elaborated on the significance of ecological and epidemiological studies on the occurrence of pathogenic Nocardia spp in the soil and environment [29]. 


\section{Cureus}

\section{Laboratory identification of Nocardia spp}

Laboratory diagnosis of human nocardiosis includes microscopy and culture. Identification of Nocardia is more rapid, precise, and accurate with polymerase chain reaction (PCR) and 16S rDNA sequencing than with conventional phenotypic methods, which include microscopic, cultural, and biochemical properties [30-32]. Modified acid-fast staining using 1\% sulphuric acid as a decolorizer is employed to identify Nocardia microscopically in clinical samples, where pink colored filamentous branching bacilli are observed as shown in Figure 1.

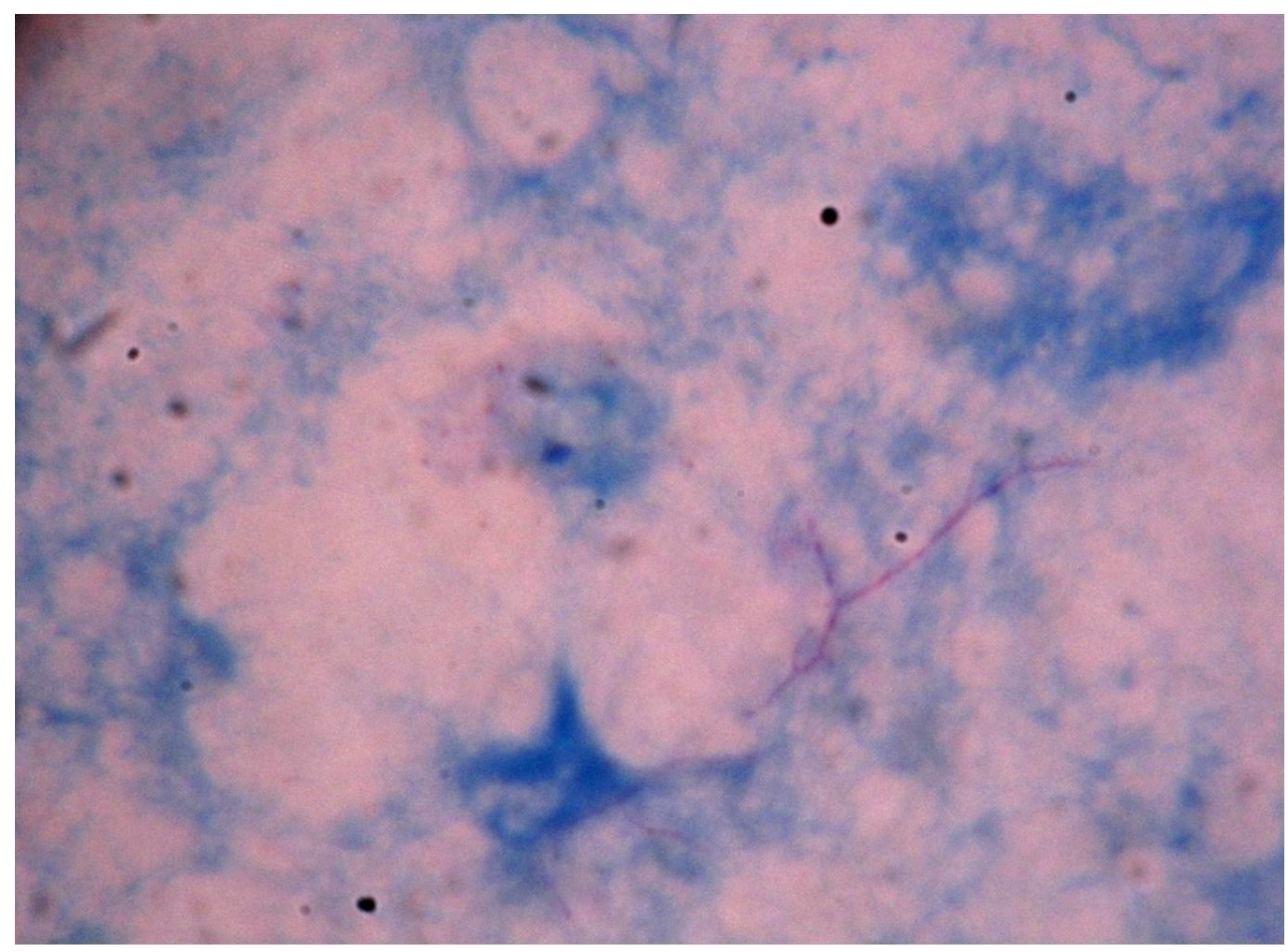

FIGURE 1: Pink colored filamentous and branched bacilli appearing in modified acid fast stained smear of respiratory secretions

N. asteroides grows well on Lowenstein-Jensen's medium (LJ medium) when incubated between $30^{\circ} \mathrm{C}$ and $37^{\circ} \mathrm{C}$. Nocardia spp also grow readily on blood agar and Saboraud's dextrose agar (SDA). Agar medium enriched with yeast extract (buffered charcoal yeast extract agar (BCYEA)) may improve the chances of isolation from clinical specimens. Colonies of Nocardia spp usually appear after 48 hours of incubation and a visible growth may take more than one week for some species. Laboratories may fail to isolate Nocardia from clinical specimens if plates are discarded after 48 hours, as regularly followed in most parts of the world. Application of molecular methods is recommended to identify the suspected human nocardiosis using multi-locus sequence analysis (MLSA) to reduce underreporting and misdiagnosis and is important for clinical and epidemiological purposes [33]. A recent report from Brazil has noted $0.12 \%$ of the sputum samples collected from patients suspected to be suffering from infection with Mycobacterium tuberculosis (Pulmonary tuberculosis) have grown Nocardia in LowensteinJensen's medium. This study has also elaborated on the significance of a presumptive clinical diagnosis in the improvement of laboratory isolation of Nocardia spp from clinical samples [34]. 


\section{Antimicrobial chemotherapy in nocardiosis}

Although Nocardia spp are susceptible to most of the penicillin and cephalosporin group of antibiotics, the cause of concern is the probability of the emergence of antimicrobial resistance among some species $[8,35]$. Antibiotics effective against gram-positive bacteria, including linezolid, ampicillin, erythromycin, and minocycline are used to treat nocardiosis. Considering the emergence of antibiotic resistance a combination of sulfonamide (trimethoprim/ sulfamethoxazole), ceftriaxone and amikacin may be preferred to treat human nocardiosis [36]. A recent paper has highlighted the significance of the organ involved, its antimicrobial susceptibility pattern, and the use of combination antibiotic therapy in the treatment of human nocardiosis [37]. A ten-year retrospective study of antibiotic susceptibility patterns of Nocardia spp isolated from the United States of America revealed that more than $50 \%$ isolates were resistant to trimethoprim/sulfamethoxazole (TMP/SMX). This study has also recommended that a combination therapy including TMP/SMX, ceftriaxone and imipenem can be initiated until the sensitivity report is available [38].

\section{Conclusions}

Clinicians, chest disease specialists, and clinical microbiologists should consider carefully the possibility of human nocardiosis. Clinical microbiology laboratories must follow standard protocols when performing sputum cultures and consider isolation and identification of Nocardia spp from various clinical specimens for better patient management in case of chest infections.

\section{Additional Information}

\section{Disclosures}

Conflicts of interest: In compliance with the ICMJE uniform disclosure form, all authors declare the following: Payment/services info: All authors have declared that no financial support was received from any organization for the submitted work. Financial relationships: All authors have declared that they have no financial relationships at present or within the previous three years with any organizations that might have an interest in the submitted work. Other relationships: All authors have declared that there are no other relationships or activities that could appear to have influenced the submitted work.

\section{References}

1. Gordon MA: Aerobic Pathogenic Actinomycetaceae, Chapter 23. Manual of Clinical Microbiology, 4th ed. Lennette EH, Balows A, Hausler WJ Jr, Truant JP (ed): American Society for Microbiology, Washington, D.C; 1985. 249-62.

2. Conville PS, Witebsky FG: Nocardia, Rhodococcus, Gordonia, Actinomadura, Streptomyces, and other aerobic actinomycetes. Manual of Clinical Microbiology, 9th ed. Murray PR, Baron EJ, Jorgensen JH, Landry MI, Pfaller MA (ed): American Society for Microbiology, Washington, D.C; 2007. 515-42. 10.1128/9781555816728.ch27

3. Ramana KV, Rao R, Sharada CV, Kareem M, Reddy LR, Ratna Mani M: Modified Hodge test: A useful and the low cost Phenotypic method for detection of carbapenemase producers in Enterobacteriaceae members. J Nat Sc Biol Med. 2013, 4:346-8. 10.4103/0976-9668.117009

4. Kalaskar A, Venkataramana K: Determination of Antimicrobial Resistance Pattern and Production of Extended-Spectrum $\beta$-Lactamases amongst Escherichia coli and Klebsiella pneumoniae from Clinical Isolates. J Med Bacteriol. 2012, 1:17-24.

5. Ramana KV: Pulmonary Tuberculosis Disseminating and Presenting as Bilateral Hydronephrosis and Renal Abscess: a Potential Threat in the Era of Multi-Drug Resistant Tuberculosis MDR-TB. American Journal of Infectious Diseases and Microbiology. 2014, 2:4850. 10.12691/ajidm-2-3-2

6. Ramana KV, Sabitha K, Venkata Bharatkumar P, Sharada CHV, Ratna Rao, Ratna Mani, Sanjeev 
DR: Invasive Fungal Infections: A Comprehensive Review . American Journal of Infectious Diseases and Microbiology. 2013, 1:64-69. 10.12691/ajidm-1-4-2

7. Ramana KV, Kumar MV, Rao SD, Akhila R, Sandhya, Shruthi P, Pranuthi M, Krishnappa M, Anand K: Pulmonary Cryptococcosis Secondary to Bronchial Asthma Presenting as Type I Respiratory Failure- A Case Report with Review of Literature. Virol Mycol. 2012, 1:107. 10.4172/2161-0517.1000107

8. Nocardiosis. (2013). Accessed: May 2, 2015: http://www.cdc.gov/nocardiosis/index.html.

9. Conville PS, Brown JM, Steigerwalt AG, Judy WL, Dorothy EB, Victoria LA, Susan ED, Steven MH, Barbara C, Karen CC, Frank GW: Nocardia veterana as a Pathogen in North American Patients. J Clin Microbiol. 2003, 41:2560-2568. 10.1128/JCM.41.6.2560-2568.2003

10. Piau C, Kerjouan M, Le Mouel M, Patrat-Delon S, Henaux P-L, Brun V, Morin M-P, Gautier P, Rodriguez-Nava V, Kayal S: First case of disseminated infection with Nocardia cerradoensis in a human. J Clin Microbiol. 2015, 53:1034-1037. 10.1128/JCM.02979-14

11. Ambrosioni J, Lew D, Garbino J: Nocardiosis updated clinical review and experience at a tertiary center. Infection. 2010, 38:89-97. 10.1007/s15010-009-9193-9

12. Flateau C, Jurado V, Lemaître N, Loïez C, Wallet F, Saiz-Jimenez C, Decoene C, Bergeron E, Boiron P, Faure K, Guery B, Rodríguez-Nava V: First Case of Cerebral Abscess Due to a Novel Nocardia Species in an Immunocompromised Patient. J Clin Microbiol. 2013, 51:696-700. 10.1128/JCM.00762-12

13. Nocardia infection. (2012). Accessed: June 12, 2015: http://www.nlm.nih.gov/medlineplus/ency/article/000679.htm.

14. Al Akhrass F, Hachem R, Mohamed JA, Tarrand J, Kontoyiannis DP, Chandra J, Ghannoum M, Haydoura S, Chaftari AM, Raad I: Central Venous Catheter-associated Nocardia Bacteremia in Cancer Patients. Emerg Infect Dis. 2011, 17:1651-1658. 10.3201/eid1709.101810

15. Yildiz O, Doganay M: Actinomycoses and Nocardia pulmonary infections. Curr Opin Pulm Med. 2006, 12:228-234.

16. Lerner PI: Nocardiosis. Clin Infect Dis. 1996, 22:891-903. 10.1093/clinids/22.6.891

17. Wilson JW: Nocardiosis: Updates and Clinical Overview. Mayo Clin Proc. 2012, 87:403-407. 10.1016/j.mayocp.2011.11.016

18. Saubolle MA, Sussland D: Nocardiosis: Review of Clinical and Laboratory Experience. J Clin Microbiol. 2003, 41:4497-4501. 10.1128/JCM.41.10.4497-4501.2003.

19. Lebeaux D, Morelon E, Suarez F, Lanternier F, Scemla A, Frange P, Mainardi J-L, Lecuit M, Lortholary O: Nocardiosis in transplant recipients. Eur J Clin Microbiol Infect Dis. 2014, 33:689-702.

20. Sorrell TC, Mitchell DH, Iredell JR, Chen SC-A: Nocardia Species. Mandell, Douglas, and Bennett's principles and practice of infectious diseases. Mandell GL, Bennett JE, Dolin R (ed): Churchill Livingston, Philadelphia, PA; 2010. 3199-3207.

21. Beaman BL, Beaman L: Nocardia species: host-parasite relationships. Clin Microbiol Rev. 1994, 7:213-264.

22. Patil M, Shivaprasad C,Varghese J, Rajagopalan N: A fatal case of pulmonary nocardiosis . BMJ Case Rep. 2012, 2012:bcr0920114875. 10.1136/bcr.09.2011.4875

23. Chedid Maria Bernadete F, Chedid Marcio F, Porto Nelson S, Severo Cecília B, Severo Luiz Carlos: Nocardial infections: report of 22 cases . Rev. Inst. Med. trop. S Paulo. 2007, 49:239246. 10.1590/S0036-46652007000400009

24. Navarrete-Navarrete N, Sevilla JE, García MT, Urbano F, Sabio JM, Jiménez-Alonso J: A Man with Unilateral Endophthalmitis: A Case of Disseminated Nocardiosis,. Case Reports in Infectious Diseases. 2015, Article ID 607421. 10.1155/2015/607421

25. Özgenç, Onur, Avcı, Meltem, Arı, Alpay, Çelebi, İsmail Yunus, Coşkuner, Seher Ayten: Longterm treatment of persistent disseminated Nocardia cyriacigeorgica infection. Braz J Infect Dis. 2014, 18:556-560. Accessed: June 27: http://www.scielo.br/scielo.php? script=sci_arttext \&pid=S1413-86702014000500556\&lng=en\&tlng=pt. 10.1016/j.bjid.2014.03.007

26. Martínez R, Reyes S, Menéndez R: Pulmonary nocardiosis: risk factors, clinical features, diagnosis and prognosis. Curr Opin Pulm Med. 2008, 14:219-227. 10.1097/MCP.0b013e3282f85dd3

27. Yagi K, Ishii M, Namkoong H, Asami T, Fujiwara H, Nishimura T, Saito F, Kimizuka Y, Asakura T, Suzuki S, Kamo T, Tasaka S, Gonoi T, Kamei K, Betsuyaku T, Hasegawa N: Pulmonary nocardiosis caused by Nocardia cyriacigeorgica in patients withMycobacterium avium 
Complex lung disease: two case reports. BMC Infect Dis. 2014, 14:684. 10.1186/s12879-0140684-Z

28. Kanne JP, Yandow DR, Mohammed TL, Meyer CA: CT Findings of Pulmonary Nocardiosis. AJR Am J Roentgenol. 2011, 197:266-72. 10.2214/AJR.10.6208

29. Andalibi F, Mehdi FB, Parvin H, Masoumeh RN, Shadi H, Mohammad RP, Eshraghi SS: Isolation and Identification of Nocardia spp. Using Phenotypic Methods from Soil Samples of North Khorasan Province. J Med Bacteriol. 2015, 4:8-14.

30. Brown JM, McNeil M: Nocardia, Rhodococcus, Gordonia, Actinomadura, Streptomyces, and other aerobic actinomycetes. Manual of clinical microbiology. Murray PR, Baron EJ, Jorgensen JH, Pfaller MA, Yolken RH (ed): American Society for Microbiology, Washington DC; 2003. 502-531.

31. Woo PC, Lau SK, Teng JL, Tse H, Yuen KY: Then and now: use of 16S rDNA gene sequencing for bacterial identification and discovery of novel bacteria in clinical microbiology laboratories. Clin Microbiol Infect. 2008, 14:908-34. 10.1111/j.1469-0691.2008.02070.x

32. Steingrube VA, Brown BA, Gibson JL, Wilson RW, Brown J, Blacklock Z, Jost K, Locke S, Ulrich RF, Wallace Jr RJ: DNA amplification and restriction endonuclease analysis for differentiation of 12 species and taxa of Nocardia, including recognition of four new taxa within the Nocardia asteroides complex. J. Clin. Microbiol. 1995, 33:3096-3101.

33. Roth A, Andrees S, Kroppenstedt RM, Harmsen D, Mauch H: Phylogeny of the Genus Nocardia Based on Reassessed 16S rRNA Gene Sequences Reveals Underspeciation and Division of Strains Classified as Nocardia asteroides into Three Established Species and Two Unnamed Taxons. J Clin Microbiol. 2003, 41:851-856. 10.1128/JCM.41.2.851-856.2003

34. Muricy ECM, Lemes RA, Bombarda S, Ferrazoli L, Chimara E: DIFFERENTIATION BETWEEN Nocardia spp. AND Mycobacterium spp.: CRITICAL ASPECTS FOR BACTERIOLOGICAL DIAGNOSIS. Revista do Instituto de Medicina Tropical de São Paulo. 2014, 56:397-401. 10.1590/S0036-46652014000500005

35. Wallace RJ, Tsukamura M, Brown BA, J Brown, Steingrube VA, Zhang Y, Nash DR: Cefotaximeresistant Nocardia asteroides strains are isolates of the controversial species Nocardia farcinica. J. Clin. Microbiol. 1990, 28:2726-2732.

36. Nocardiosis: DBMB. (2001). Accessed: June 20, 2015: http://www.rightdiagnosis.com/artic/nocardiosis_dbmd.htm.

37. Welsh O, Vera-Cabrera L, Salinas-Carmona MC: Current treatment for Nocardia infections. Expert Opin. Pharmacother. 2013, 14:2387-2398. 10.1517/14656566.2013.842553

38. Uhde KB, Pathak S, McCullum I Jr, Jannat-Khah DP, Shadomy SV, Dykewicz CA, Clark TA, Smith TL, Brown JM: Antimicrobial-resistant nocardia isolates, United States, 1995-2004. Clin Infect Dis. 2010, 51:1445-8. 10.1086/657399 